\title{
NIR SPECTROSCOPY DETECTS CHLORPYRIFOS- Methyl PESTICIDE Residue In ROUGH, BROWN, AND MILLED RICE
}

\author{
F. S. Rodriguez, P. R. Armstrong, E. B. Maghirang, K. F. Yaptenco, E. D. Scully, \\ F. H. Arthur, D. L. Brabec, A. D. Adviento-Borbe, D. C. Suministrado
}

\begin{abstract}
HighLIGHTS
- NIR spectroscopy detects quantitative and qualitative levels of chlorpyrifos-methyl residues in bulk rice.

- Levels of chlorpyrifos-methyl residues in bulk rice can be differentiated at $78 \%$ to $100 \%$ correct classification.

- Important NIR wavelengths for chlorpyrifos-methyl residue detection were identified.

- NIR spectroscopy can be used to detect maximum residue levels of chlorpyrifos-methyl pesticide in rice.
\end{abstract}

\begin{abstract}
A rapid technique that uses near-infrared reflectance (NIR) spectroscopy for simultaneous qualitative and quantitative determination of the presence of varying concentrations of chlorpyrifos-methyl in bulk samples of rough, brown, and milled rice was established. Five rice varieties, free of pesticides, obtained from RiceTec Inc. and USDA-ARS Arkansas experimental field were used as rough rice samples and also processed to obtain corresponding brown and milled rice. Rice samples were treated with Storcide ${ }^{T M}$ II containing varying levels of the active ingredient, chlorpyrifos-methyl: 0, 1.5, 3, 6, 9, and $12 \mathrm{ppm}$ for rough rice, 0, 0.75, 1.5, 3, 4.5, and $6 \mathrm{ppm}$ for brown rice, and 0, 0.1, 0.2, 0.4, 0.6, and 0.8 ppm for milled rice. Concentrations of chlorpyrifos-methyl were verified using gas chromatography-mass spectrometry analyses. A commercial NIR spectrometer (950-1650 $\mathrm{nm}$ wavelength range) was used to obtain spectra of bulk samples. Using partial least squares analysis for quantitative analysis, independent validation showed that chlorpyrifos-methyl residues in rough, brown, and milled rice are predictable with $R^{2}$ ranging from 0.702 to 0.839 and standard error of prediction (SEP) of 1.763 to 2.374 for rough rice, $R^{2}$ ranging from 0.722 to 0.800 and SEP of 0.953 to 1.168 for brown rice, and $R^{2}$ ranging from 0.693 to 0.789 and SEP of 0.131 to 0.164 for milled rice. For qualitative analysis obtained using discriminant analysis, rough rice samples with concentrations of $0,1.5$, and 3 ppm pooled as low pesticide level (LPL) is distinguishable to 6, 9, and $12 \mathrm{ppm}$ which were pooled as high pesticide level (HPL). Similarly, for brown and milled rice, the lower three concentrations pooled as LPL is distinguishable from the higher three concentrations pooled as HPL. Independent validation showed overall correct classifications ranging from $77.8 \%$ to $92.6 \%$ for rough rice, $79.6 \%$ to $88.9 \%$ for brown rice, and $94.4 \%$ to $100 \%$ for milled rice.

NonCommercial-NoDerivatives 4.0 International License https:/creative commons.org/licenses/by-nc-nd/4.0/.

Submitted for review in March 2020 as manuscript number PRS 14001; approved for publication as a Research Article by the Processing Systems
\end{abstract} Community of ASABE in October 2020.

The mention of a trademark or proprietary product does not constitute a guarantee or warranty of the product by the USDA and does not imply its approval for the exclusion of other products that may also be suitable. USDA is an equal opportunity provider and employer.

The authors are Fatima S. Rodriguez, Faculty, Don Mariano Marcos Memorial State University, Bacnotan, La Union, Philippines; Ph.D. Graduate Student, University of the Philippines Los Baños (UPLB), Los Baños, Laguna, Philippines; and Visiting Scholar, ARS-USDA, Manhattan, Kansas; Paul R. Armstrong, Research Agricultural Engineer, and Elizabeth B. Maghirang, Agricultural Engineer, Center for Grain and Animal Health Research (CGAHR), ARS-USDA, Manhattan, Kansas; Kevin F. Yaptenco, Professor, UPLB, College of Engineering and AgroIndustrial Technology, Los Baños, Laguna, Philippines, Erin D. Scully, Research Molecular Biologist, Frank H. Arthur, Research Entomologist, and Daniel L. Brabec, Research Agricultural Engineer, CGAHR, USDAARS, Manhattan, Kansas; Arlene D. Adviento-Borbe, Research Agronomist, Delta Water Management Research Unit, USDA-ARS, Jonesboro, Arkansas; and Delfin C. Suministrado, Professor, UPLB, College of Engineering and Agro-Industrial Technology, Los Baños, Laguna, Philippines. Corresponding author: Fatima S. Rodriguez, Don Mariano Marcos Memorial State University, Bacnotan, La Union, Philippines; e-mail: fatima_rodz@yahoo.com, or Paul Armstrong, USDAARS, 1515 College Avenue, Manhattan, KS 66502; phone: 785-776-2730; e-mail: paul.armstrong@usda.gov.

Keywords. Food safety, Grain quality, NIR spectroscopy, Pesticide residue, Rice.

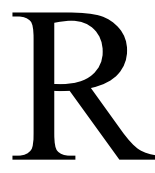
ice is the most consumed staple food by the human population, especially in Asian countries, making it imperative that rice consumer safety is given high priority. The presence of pesticide residues in various rice types and the possible adverse effects on human health associated with consuming residues present a major concern for producers, consumers, scientists, and regulatory agencies. In response, the Food and Agriculture Organization (FAO) of the United Nations and the World Health Organization (WHO) in their joint food standards program, Codex Alimentarius Commission, continuously monitor, update, and impose maximum residue levels (MRL) for pesticides in numerous commodities, including rice. For example, FAO/WHO have set MRLs for 
chlorpyrifos-methyl in rough, brown, and milled rice at 10 , 1.5 , and $0.2 \mathrm{ppm}$, respectively (Codex Alimentarius Commission, 2017).

Gonzales-Curbelo et al. (2012) compiled and reviewed occurrence of pesticides in cereal grains and observed that residues were mainly found in grains sampled from USA, EU, Korea, India, and China while none were found from South America, Africa, or Australia. This study showed that the pesticides most frequently found were insecticides (including chlorpyrifos-methyl, pyrimiphos methyl,chlorpyrifos, malathion, dichlorodiphenylethanes and dihexachlorocyclohexanes), and occurred mainly in wheat and rice. Organophosphates are among the most commonly used insecticides to treat fruits, vegetables and grains infested by insects and weevils. When applied according to manufacturer recommendations, use of these organophosphates are considered safe and should not have an adverse impact on public health. This finding was supported by Zhang et al. (2012) where husked rice, rice hull, and straw samples obtained from paddy fields treated with the recommended dosage of chlorpyrifos were found to contain residues well below the MRL.

Chlorpyrifos-methyl is one of the organophosphates commonly used to eradicate insects and weevils in rice grain warehouses. Analyses performed by official European Union laboratories on more than 3000 rice samples showed that $6 \%$ have pesticide residue levels above the pesticide MRL (Pareja et al., 2011). Additional concerns regarding rice pesticide residues were confirmed by studies that indicated that excessive application of chlorpyrifos can have adverse effects on human health and the environment. Experiments done with rats showed a significant decrease in the height of their cerebral hemisphere at top dose $(50 \mathrm{ppm})$ of chlorpyrifos-methyl (EFSA, 2019). Likewise, based on independent epidemiological, in vivo and in vitro studies, the evidence points to adverse health effects of chlorpyrifos exposure on the developing nervous system, associated with lowered IQ at school age (Mie et al., 2018). Degradation of chlorpyrifosmethyl in air, water, and soil were shown to result to environmental pollution. The metabolic breakdown product of chlorpyrifos and chlorpyrifos-methyl, 3, 5, 6, trichloro-2 pyridinol showed harmful effects on human health through pesticide inhalation, aquatic life through water and other environmental effects of hazardous waste constituents (U.S. EPA, 1984). Gas chromatography (GC), with mass spectrometry (GC-MS) or liquid chromatography/tandem mass spectrometry are commonly used to test for pesticide residues. Although these methods are generally considered highly quantitative and accurate for pesticide residue measurement, they are time-consuming and labor-intensive due to complicated sample preparation and instrument operation, and screening large numbers of samples. In addition, the chemical composition of rice can lead to difficulty in extracting and detecting pesticide residues as its composition may create interference in the pesticide residue detection process (Gonzales-Curbelo et al., 2012). Thus, other high throughput screening techniques for more rapid detection of pesticide residues have been investigated. Kim et al. (2007) developed an acetylcholinesterase detection kit, based on a modification of Ellman and ELISA methods for the detection of organophosphorus ( 0.50 to $2.50 \mathrm{ppm}$ detection limit) and carbamate $(0.50$ to $4.75 \mathrm{ppm}$ detection limit) pesticides in agricultural samples. The use of this kit resulted in substantial decrease in cost and time compared to antibody-based immunoassays that require expensive equipment. Sanyal et al. (2009) developed a multi-residue method to determine organophosphorous residues in cooked and polished rice using accelerated solvent extraction and dispersive-solid phase extraction. Rungchang et al. (2018) used a multi-purpose analyzer (MPA) FT-NIR to determine carbofuran pesticide levels in Thai Jasmine paddy rice. When using dry extract samples, they showed that NIR spectroscopy was effective for determining carbofuran contamination in paddy rice.

The continuing and compelling need to ensure a safe supply of rice coupled with the need for monitoring and detecting pesticide residues to ensure compliance with MRLs mandated by legislation, highlights the importance of developing fast and effective techniques. Aside from the typical use of NIR spectroscopy for measurement of moisture, starch, ash, and protein contents in rice, it has long proven to be a technique that allows for fast and accurate detection of numerous contaminants or conditions of rice, such as presence of arsenic in rice, storage age, and cross-contamination of rice varieties and transgenics (Osborne et al., 1993; Font et al., 2005; Liu et al., 2006; Attaviroj et al., 2011; Chuang et al., 2014; Xu et al., 2014). However, this technique has not yet been applied for detection of residues of organophosphates in rice. The objective of this study is to develop a NIR spectral technique for quick detection of the presence of pesticide residues containing varying concentrations of chlorpyrifos-methyl for different rice types (rough rice, brown rice, and milled rice). The existing MRLs provided by the $\mathrm{FAO} / \mathrm{WHO}$ at $10,1.5$, and $0.2 \mathrm{ppm}$ for rough, brown, and milled rice served as basis for pesticide concentrations evaluated in this study.

\section{Materials ANd Methods \\ Rice SAMPLES}

Five pesticide-free rice varieties (CL151, Hybrid 1, Diamond, Gemini, and Hybrid 2) harvested from the experimental field of RiceTec Research Station and the Delta Water Management Research Unit of the Agricultural Research Service- U.S. Department of Agriculture (ARSUSDA) located in Harrisburg, Arkansas, were obtained. Upon arrival at the Center for Grain and Animal Health Research (CGAHR) ARS-USDA, Manhattan, Kansas, all rough or paddy rice (fig. 1) samples were cleaned using the Carter Day dockage tester (Carter Day International, Minneapolis, Minn.) following the prescribed instrument settings for rough rice cleaning. The cleaned rough rice samples (fig. 1) were conditioned to $14 \%$ moisture content by spreading the samples into thin layers in aluminum trays and holding them in a Percival Intellus Control System environmental chamber (Percival Scientific, Fontana, Wis.) set at $23^{\circ} \mathrm{C}$ and $73 \%$ relative humidity (RH) for three (3) days. Three sub-samples of the rough rice were divided using a Boerner sample divider (Seedburo Equipment, Des Plaines, Ill.) in order to obtain sample sizes that would 
provide $\sim 1980 \mathrm{~g}$ of rough, brown, and milled rice for each of the five (5) varieties. The rough rice sample portions for producing brown (also known as dehulled) and milled (also known as polished) rice samples (fig. 1) were dehulled using the JLGL-45 rubber roll rice husker (Wuhan Acme AgroTech Co. Ltd., Wuhan, China). The brown rice portion for producing milled rice were polished using the Twinbird MRE500 (Twinbird Corp., China). From the $\sim 1980 \mathrm{~g}$ samples of rough, brown, and milled rice, sub-samples of $110 \mathrm{~g}$ were obtained by dividing the rice samples further using the Boerner divider (Seedburo Equipment, Des Plaines, Ill.), i.e., 90 sub-samples for each rice type. Each of the $110 \mathrm{~g}$ rough rice and milled rice were placed in sealed $32 \mathrm{oz}$ clear, polyethylene terephthalate wide-mouth plastic jars. To address the reported instability of brown rice during storage (Liu et al., 2016), the brown rice samples were vacuum sealed using FoodSaver Vac 360 (Sunbeam Products, Inc., Boca Raton, Fla.) and were kept vacuum sealed in between sample analysis.

\section{Pesticide (Chlorpyrifos-Methyl Solution) PREPARATION AND APPLICATION}

Storcide $^{\mathrm{TM}}$ II (Bayer CropScience, Research Triangle Park, N.C.), a liquid grain protectant used to control insect infestations and maintain grain quality within a 6 to 12 months storage period, was used for this study. The Storcide $^{\mathrm{TM}}$ II concentrate contains (a) active ingredients of chlorpyrifos-methyl $\left(\mathrm{C}_{7} \mathrm{H}_{7} \mathrm{Cl}_{3} \mathrm{NO}_{3} \mathrm{PS}, 21.60 \%\right)$ and pyrethroid deltamethrin $\left(\mathrm{C}_{22} \mathrm{H}_{19} \mathrm{Br}_{2} \mathrm{NO}_{3}, 3.70 \%\right)$ and (b) inert ingredients of solvent naphtha (petroleum) light aromatic (no molecular formula and structure provided, 39.40\%), 1,2,4trimethybenzene $\left(\mathrm{C}_{9} \mathrm{H}_{12}, 18.60 \%\right)$, xylene $\left(\mathrm{C}_{8} \mathrm{H}_{10}, 7.20 \%\right)$, mesitylene $\left(\mathrm{C}_{9} \mathrm{H}_{12}, 1.90 \%\right)$, ethylbenzene $\left(\mathrm{C}_{8} \mathrm{H}_{10}, 1.40 \%\right)$ and cumene $\left(\mathrm{C}_{9} \mathrm{H}_{12}, 1.00 \%\right)$ (Bayer Crop Science, 2016; PubChem, n.d.). The chemical structure of chlorpyrifos-methyl is shown in figure 2 .

Based on the manufacturer's recommendation, the concentrate is normally diluted for rice using $275 \mathrm{~mL}$ per 5 gal of water for application to 1000 bushels of grain. This dilution and application provide $\sim 3 \mathrm{ppm}$ of chlorpyrifos-methyl to the grain. With the concentration of chlorpyrifos-methyl as the focus of imposed MRLs, such as those provided by the FAO, this study used varying chlorpyrifos-methyl concentrations in Storcide ${ }^{\mathrm{TM}}$ II pesticide

Storcide $^{\mathrm{TM}}$ II was diluted with water to attain the target concentrations of chlorpyrifos-methyl for rough rice $(1.5,3$,

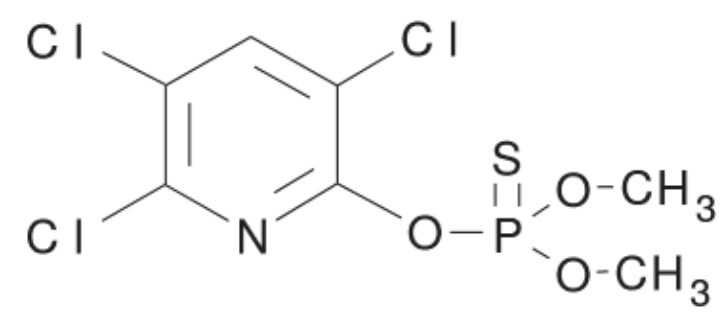

Figure 2. Chemical structure of chlorpyrifos-methyl (Source: FAO/ WHO, 2009).

$6,9$, and $12 \mathrm{ppm})$, brown rice $(0.75,1.5,3,4.5$, and $6 \mathrm{ppm})$ and milled rice $(0.1,0.2,0.4,0.6$, and $0.8 \mathrm{ppm})$. All liquid treatments were applied using a Badger Model 100 air brush (Badger Air-Brush Co., Franklin Park, Ill.) fitted with a medium tip and operated at an air pressure of $10 \mathrm{psi}$. All sample treatments were done under a fume hood for ventilation purposes. In order to eliminate the potential effect of varying moisture content, each of the $110 \mathrm{~g}$ samples, i.e., control and pesticide-treated samples, were sprayed with $0.2 \mathrm{~mL}$ of liquid. The control samples (no pesticide applied) from each rice type were spread onto a layer of kraft paper and sprayed evenly with $0.2 \mathrm{~mL}$ water. The rest of the samples to be treated with varying levels of pesticide were sprayed evenly with $0.2 \mathrm{~mL}$ of corresponding solutions. Each treated sample was immediately placed in the plastic jar and manually tumbled continuously for $20 \mathrm{~s}$ to allow blending and homogenous distribution of the pesticide. Samples in the sealed plastic jars were kept for $\sim 24 \mathrm{~h}$ to allow equilibration within the container under ambient conditions $\left(\sim 24^{\circ} \mathrm{C}\right.$ and $\sim 32 \%$ $\mathrm{RH})$. The pesticide applications were scheduled so that collection of spectra was started within $\sim 24 \mathrm{~h}$ after application and completed on the same day.

\section{NIR SPECTRAL DATA ACQUISITION}

The spectra of $100 \mathrm{~g}$ bulk rice samples ( 950 to $1650 \mathrm{~nm}$ ) were obtained using the Perten DA7200 NIR analyzer (Perten Instruments, Hagersten, Sweden). The bulk sample was poured in the sample dish ( $76 \mathrm{~mm}$ dia and $38 \mathrm{~mm}$ deep) and leveled before placing in the NIR instrument. The instrument was set to obtain spectra in rotating mode for three (3) replicates with three repacks for each sample. The spectra from three repacks were averaged. In order to ensure that there were no cross-contaminations of pesticide residues, the dish was washed with soap and water after spectral data collection of each pesticide concentration and then immediately dried using compressed air.

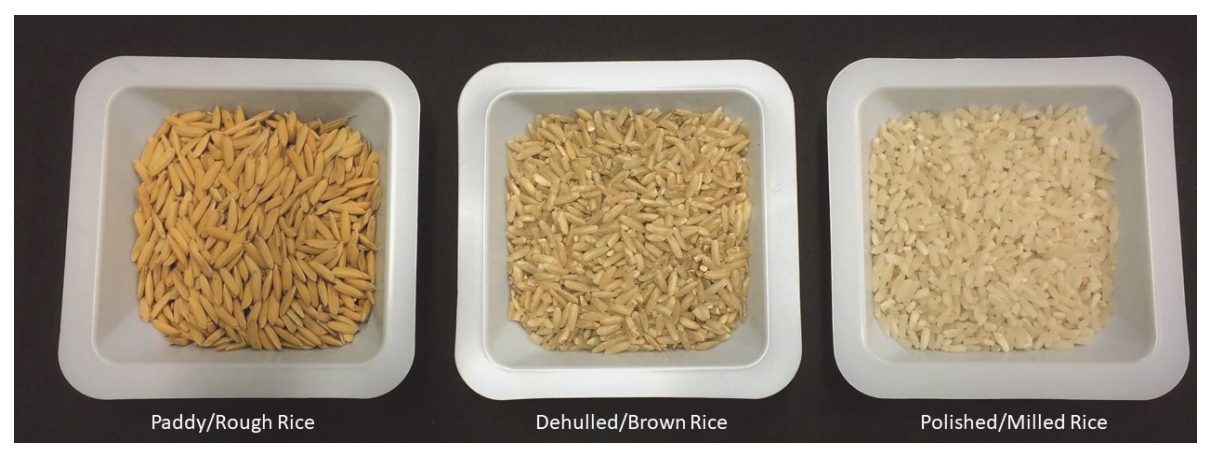

Figure 1. Rough (paddy), brown (dehulled), and milled (polished) rice samples. 
VALIDATION OF CHLORPYRIFOS-METHYL

\section{CONCENTRATION IN TREATED RICE SAMPLES}

Gas Chromatography/Mass Spectroscopy (GS/MS) was performed using an Agilent Technologies 7890B GC System coupled with a 5977B Mass Spectrometer (Agilent, Santa Clara, Calif.) and Gerstel MPS liquid, headspace, and SPME autosampler (Gerstel, Linthicum, Md.) to validate chlorpyrifos-methyl concentrations applied to the samples and confirm that the control samples used were free of chlorpyrifosmethyl. Ten-grams of each sample was ground using a Wiley Mill Model 474A (Thomas Scientific, Swedesboro, N.J.) and kept frozen at $-20^{\circ} \mathrm{C}$ prior to extraction and GC/MS analysis. Extraction of chlorpyrifos-methyl residues was performed using a modification of the protocol described by Kolberg (2011). In brief, residues were extracted from $5 \mathrm{~g}$ of each sample in $15 \mathrm{~mL}$ acetonitrile ( $>99.8 \%$ for HPLC, VWR, Radnor, Pa.) and the QuEChERs method (Quick, Easy, Cheap, Effective, Rugged, and Safe, Agilent, Santa Clara, Calif.) was used to reduce fatty acids, sterols, lipids, and sugars in the sample prior to GC/MS analysis. For this method, $4.0 \mathrm{~g}$ magnesium sulfate and $1.0 \mathrm{~g}$ sodium chloride were added to the acetonitrile and were vortexed briefly. The upper phase was transferred to a $15 \mathrm{~mL}$ centrifuge tube containing $400 \mathrm{mg}$ primary and secondary amine exchange material, $400 \mathrm{mg} \mathrm{C18}$, and $1200 \mathrm{mg}$ magnesium sulfate and was vortexed thoroughly. After centrifugation at about $3500 \mathrm{rpm}$, the upper layer containing acetonitrile was transferred to a new $50 \mathrm{~mL}$ tube and evaporated to dryness with nitrogen at 5 psi. Samples were resuspended in $500 \mu \mathrm{L}$ of acetonitrile containing $100 \mu \mathrm{g}$ of triphenylphosphate as an internal GC standard. Aliquots of $1.0 \mu \mathrm{L}$ of each extract were injected into the GC, which was equipped with an Agilent HP-5MS column. The injection port was maintained at $250^{\circ} \mathrm{C}$ and $15 \mathrm{psi}$ and was run in splitless mode. The GC oven program was $55^{\circ} \mathrm{C}$ for $2.0 \mathrm{~min}$, followed by a $30^{\circ} \mathrm{C} \mathrm{min}^{-1}$ ramp to $170^{\circ} \mathrm{C}$ and a final ramp of $5^{\circ} \mathrm{C} \mathrm{min}^{-1}$ to $280^{\circ} \mathrm{C}$ (held for $15 \mathrm{~min})$ and helium was used as the carrier gas as $(99.99 \%$ purity; Matheson, Irving, Tex.) at a constant flow-rate of $1.3 \mathrm{~mL} \mathrm{~min}^{-1}$. The MS was run in select ion mode (SIM) and each compound was quantified based on the peak area of three quantifier ions. Laboratory standards of chlorpyrifosmethyl were also analyzed.

\section{Data ANalysis}

Quantitative and qualitative spectral data analyses were performed by partial least squares (PLS) regression and discriminant analysis, respectively, using the UnscramblerX version 10.5.1 (CAMO Software, Oslo, Norway). For the quantitative analysis, each of the 270 spectral data were assigned " 0 " for the control and the corresponding spiked chlorpyrifos-methyl concentration as reference values. GC/MS data was used to confirm that the control samples were free of chlorpyrifos -methyl and to validate the concentrations of chlorpyrifos-methyl applied to the test samples. Various partial least squares (PLS) calibration models were developed by using all the samples but with no independent validation and then using the one-variety-out technique wherein a complete set of data $(n=54)$ for a variety is taken out when developing the calibration $(n=216)$ and then is used as the validation sample set. Five calibration models were developed for each rice type. Various pre-treatments, e.g., mean centering, standard normal variate (SNV), multiplicative scatter correction (MSC), and derivative preprocessing techniques, were employed. Results from SNV and MSC showed slight improvement compared to simply using mean centering.

The statistical measures/indicators used to evaluate the performance of the model included number of factors, coefficient of determination for calibration $\left(\mathrm{R}^{2} \mathrm{cal}\right)$, cross-validation $\left(\mathrm{R}^{2} \mathrm{val}\right)$ and independent validation $\left(\mathrm{R}^{2}\right)$, root mean square error of calibration (RMSEC), standard error of cross validation (SECV), and standard error of independent validation or prediction (SEP). The SEP provides a measure of the accuracy of the prediction based on an independent set of samples.

For qualitative analysis, the six levels of chlorpyrifos-methyl concentration were pooled into two groups: (a) low pesticide level (LPL) and (b) contaminated or high pesticide level (HPL). For rough rice, the LPL group included 0, 1.5, and $3 \mathrm{ppm}$ while the HPL included 6, 9, and $12 \mathrm{ppm}$. For brown rice, the LPL group included $0,0.75$, and $1.5 \mathrm{ppm}$ and HPL included 3, 4.5, and $6 \mathrm{ppm}$. The milled rice had 0, 0.1, and $0.2 \mathrm{ppm}$ for LPL and $0.4,0.6$, and $0.8 \mathrm{ppm}$ for HPL. These cutoffs categorized brown and milled rice to be LPLs at the WHO-prescribed MRL levels of $1.5 \mathrm{ppm}$, and $0.2 \mathrm{ppm}$, respectively, and was set at a stricter $3 \mathrm{ppm}$ level for rough rice. A value of "1" was assigned to LPL and " 2 " for HPL samples for discriminant analysis. The same ALL and one-variety-out sample selection procedures that were used in the quantitative analysis were used for developing the discriminant calibration models. The statistical measures used to evaluate the performance of the prediction models included the percentage of false positive and false negative predictions. False positives occur when the low level chlorpyrifos-methyl concentration is categorized as high whereas false negatives occur when a high level is classified as low concentration.

Focusing on being able to provide the proof of concept (POC) that NIR can be used for quantitative and qualitative detection of levels of chlorpyrifos-methyl in the three rice types, all prediction models developed made use of the entire wavelength range (950 to $1650 \mathrm{~nm}$ ). Results from the PLS analysis should provide indication of the relevant wavelength ranges which can be considered when developing prediction models that utilizes identified wavelength ranges. Likewise, different pre-processing methods were evaluated, including mean centering, multiplicative scatter correction, and standard normal variate, which yielded close prediction capabilities. For current POC purposes, results from the use of the simplest pre-treatment, i.e., mean centering, are presented. It is recognized that there are pre-processing methods and combination of pre-processing techniques that can further improve the calibration model. These were not pursued further for this study, but it is foreseen that the use of various preprocessing techniques and selection of reduced wavelength range will improve the prediction capability and should be evaluated further in the development of actual calibrations for specific rice types and instruments. 


\section{RESULTS AND DISCUSSION}

VALIDATING CHLORPYRIFOS-METHYL CONCENTRATION IN RICE GRAINS USING GC/MS

The concentrations of chlorpyrifos-methyl applied to the five rice varieties of the three rice types (rough, brown, and milled rice) were measured based on the relative abundance of the major ion derived from an internal standard (triphenylphosphate) and analyzed using ANOVA followed by Tukey post-hoc mean separations (table 1). In all of the control samples, i.e., pesticide-free rice, no chlorpyrifos-methyl residues were detected but peaks corresponding to the retention time of chlorpyrifos-methyl were detected in almost all of the pesticide-treated samples with the exception of several of the $0.1 \mathrm{ppm}$ polished rice treatments.

GC/MS showed varying abilities to distinguish among different concentrations of chlorpyrifos-methyl that were applied to the different types of rice. For rough and brown rice samples, GC/MS was able to verify that there are differences in the applied chlorpyrifos-methyl concentrations in many of the varieties. For example, variation in chlorpyrifos-methyl concentrations for Hybrid 1, Diamond, and Hybrid 2 showed clear differentiation whereas results for CL151 and Gemini were slightly more variable. For Gemini rough rice, the high chlorpyrifos-methyl concentrations $(12,9$, and $6 \mathrm{ppm})$ were

Table 1. Summary of GC/MS results for determination of relative concentration of chlorpyrifos-methyl in control (not treated) and chlorpyrifos-methyl-treated rice samples.

\begin{tabular}{|c|c|c|c|c|c|c|}
\hline \multirow[b]{3}{*}{ Variety } & \multicolumn{6}{|c|}{ Chlorpyrifos-methyl Concentration in Rice } \\
\hline & \multicolumn{2}{|c|}{ Rough Rice } & \multicolumn{2}{|c|}{ Brown Rice } & \multicolumn{2}{|c|}{ Milled Rice } \\
\hline & $\begin{array}{l}\text { Applied } \\
\text { (ppm) }\end{array}$ & $\mathrm{GC}^{-} \mathrm{MS}^{[\mathrm{a}]}$ & $\begin{array}{l}\text { Applied } \\
(\mathrm{ppm})\end{array}$ & ${\mathrm{GC}-\mathrm{MS}^{[\mathrm{a}]}}$ & $\begin{array}{c}\text { Applied } \\
(\mathrm{ppm})\end{array}$ & $\mathrm{GC} \mathrm{MS}^{[\mathrm{a}]}$ \\
\hline \multirow{6}{*}{ CL151 } & 12.0 & $\mathrm{a}$ & 6.0 & $\mathrm{a}$ & 0.8 & $\mathrm{a}$ \\
\hline & 9.0 & $\mathrm{a}$ & 4.5 & $\mathrm{~b}$ & 0.6 & $\mathrm{a}$ \\
\hline & 6.0 & $\mathrm{~b}$ & 3.0 & $\mathrm{c}$ & 0.4 & $\mathrm{a}$ \\
\hline & 3.0 & $\mathrm{c}$ & 1.5 & d & 0.2 & $\mathrm{a}$ \\
\hline & 1.5 & $\mathrm{~d}$ & 0.75 & $\mathrm{~d}$ & 0.1 & nd \\
\hline & 0 & $\mathrm{nd}^{[\mathrm{b}]}$ & 0 & nd & 0 & nd \\
\hline \multirow{6}{*}{ Hybrid 1} & 12.0 & $\mathrm{a}$ & 6.0 & $\mathrm{a}$ & 0.8 & $\mathrm{a}$ \\
\hline & 9.0 & b & 4.5 & b & 0.6 & b \\
\hline & 6.0 & c & 3.0 & $\mathrm{c}$ & 0.4 & b \\
\hline & 3.0 & d & 1.5 & d & 0.2 & $\mathrm{c}$ \\
\hline & 1.5 & $\mathrm{e}$ & 0.75 & $\mathrm{e}$ & 0.1 & $\mathrm{c}$ \\
\hline & 0 & nd & 0 & nd & 0 & nd \\
\hline \multirow{6}{*}{ Diamond } & 12.0 & $\mathrm{a}$ & 6.0 & $\mathrm{a}$ & 0.8 & $\mathrm{a}$ \\
\hline & 9.0 & b & 4.5 & $\mathrm{~b}$ & 0.6 & $\mathrm{a}$ \\
\hline & 6.0 & $\mathrm{c}$ & 3.0 & $\mathrm{c}$ & 0.4 & b \\
\hline & 3.0 & d & 1.5 & d & 0.2 & $\mathrm{c}$ \\
\hline & 1.5 & $\mathrm{e}$ & 0.75 & $\mathrm{e}$ & 0.1 & nd \\
\hline & 0 & nd & 0 & nd & 0 & nd \\
\hline \multirow{6}{*}{ Gemini } & 12.0 & $\mathrm{a}$ & 6.0 & $\mathrm{a}$ & 0.8 & $\mathrm{a}$ \\
\hline & 9.0 & $\mathrm{a}$ & 4.5 & b & 0.6 & $\mathrm{a}$ \\
\hline & 6.0 & $\mathrm{a}$ & 3.0 & b & 0.4 & $a b$ \\
\hline & 3.0 & b & 1.5 & $\mathrm{c}$ & 0.2 & $\mathrm{~b}$ \\
\hline & 1.5 & $\mathrm{c}$ & 0.75 & $\mathrm{c}$ & 0.1 & nd \\
\hline & 0 & nd & 0 & nd & 0 & nd \\
\hline \multirow{6}{*}{ Hybrid 2} & 12.0 & $\mathrm{a}$ & 6.0 & $\mathrm{a}$ & 0.8 & $\mathrm{a}$ \\
\hline & 9.0 & b & 4.5 & b & 0.6 & b \\
\hline & 6.0 & $\mathrm{c}$ & 3.0 & $\mathrm{c}$ & 0.4 & $\mathrm{c}$ \\
\hline & 3.0 & $\mathrm{~d}$ & 1.5 & d & 0.2 & d \\
\hline & 1.5 & $\mathrm{e}$ & 0.75 & $\mathrm{~d}$ & 0.1 & $\mathrm{e}$ \\
\hline & 0 & nd & 0 & nd & 0 & nd \\
\hline
\end{tabular}

[a] Concentrations designated with different letters within variety for each rice type (rough, brown, and milled rice) indicated chlorpyrifos-methyl concentrations that are distinguishable from one another based on ANOVA and Tukey post-hoc mean separations.

[b] nd = not detectable. not distinguishable from one another but were easily differentiated from the low concentrations of 1.5 and 3 ppm. Similar trends were observed for all brown rice varieties, where samples with high chlorpyrifos-methyl concentrations (6, 4.5 , and $3 \mathrm{ppm}$ ) were consistently differentiated from those with low concentrations (1.5 and $0.75 \mathrm{ppm})$. For milled rice samples, GC/MS had difficulty in differentiating among concentrations that were below $0.6 \mathrm{ppm}$ for all the varieties. The relative abundances of major ion peaks derived from chlorpyrifos-methyl were too variable to reliably differentiate among the other concentrations applied to milled rice. However, concentrations of $0.8 \mathrm{ppm}$ could be differentiated from 0.4 and $0.6 \mathrm{ppm}$ in Hybrid 1 and Hybrid 2 varieties while the $0.4 \mathrm{ppm}$ treatment was differentiated from the $0.2 \mathrm{ppm}$ treatment in three varieties.

\section{NIR SPECTRA OF RICE SAMPLES}

The NIR spectra of bulk samples of five rice varieties for each rice type (rough rice, brown rice, and milled rice) with varying concentrations of chlorpyrifos-methyl applied to the rice samples were corrected for possible scattering effects (particle size) due to diverse grain size and other physical traits using multiplicative scatter correction (MSC) (figs. 3(a1), 3(b1), and 3(c1)). Results show similar absorbance across rice samples containing varying chlorpyrifos-methyl residue levels. Based on spectral subtraction between absorbance control spectra (no chlorpyrifos-methyl treatment) and spectra from varying chlorpyrifos-methyl concentrations, for each rice type, fig. 3(a2), 3(b2), and 3(c2), minimal differences to the control were evident by residue level. However, there were no consistent trends in the degree of differences for all rice types. While the trends were not observed, these differences in absorbance provided indication of the different complex chemical matrix and varying compositions for each type of rice, which was reported by Gonzales-Curbelo et al. (2012) and Pareja et al. (2011) to have contributed to the difficulty in determining pesticide residues.

\section{Quantitative Detection of Pesticide Residues}

The PLS regression coefficients for each of the one-variety-out calibration models developed for rough, brown, and milled rice are shown in figures 4(a), 4(b), and 4(c), respectively. These plots indicate the wavelengths that contributed most to the prediction capability of the models. The constituents that contributed to the detection of chlorpyrifos-methyl using NIR spectroscopy for the three rice types included: (a) methyl $(1360 \mathrm{~nm})$, amine $(1540 \mathrm{~nm})$, and NH 2v - amide $1481 \mathrm{~nm})$ for rough rice, (b) methyl $(1360 \mathrm{~nm}), \mathrm{C}=\mathrm{O} 3^{\text {rd }}$ overtone $(1450 \mathrm{~nm}), \mathrm{NH}$ primary amides $(1471 \mathrm{~nm}), \mathrm{NH} 1^{\text {st }}$ overtone $(1570 \mathrm{~nm})$ for brown rice, and methyl $(1360 \mathrm{~nm})$, $\mathrm{CH}$ methylene $(1410 \mathrm{~nm})$, and amine $(1540 \mathrm{~nm})$ for milled rice (Shenk et al., 1992; Workman and Weyer, 2008). These functional groups are related to the chemical structure of chlorpyrifos-methyl (fig. 2).

Differences in the regression peak patterns related to chlorpyrifos-methyl across rice types were observed. This may be due to the differences in the surface of the three rice types: rough rice is covered by the hull that are mainly nonstarch carbohydrates while the brown rice has bran that 


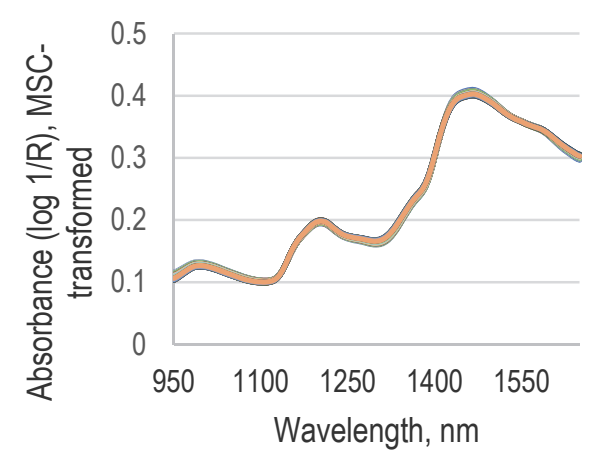

(a1) Rough rice MSC-transformed spectra

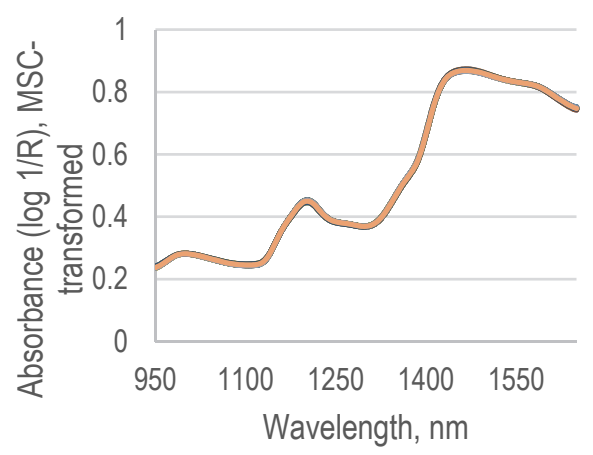

(b1) Brown rice MSC-transformed spectra

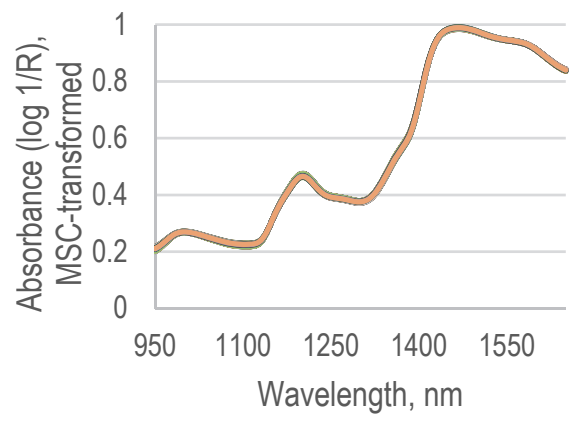

(c1) Milled rice MSC-transformed spectra

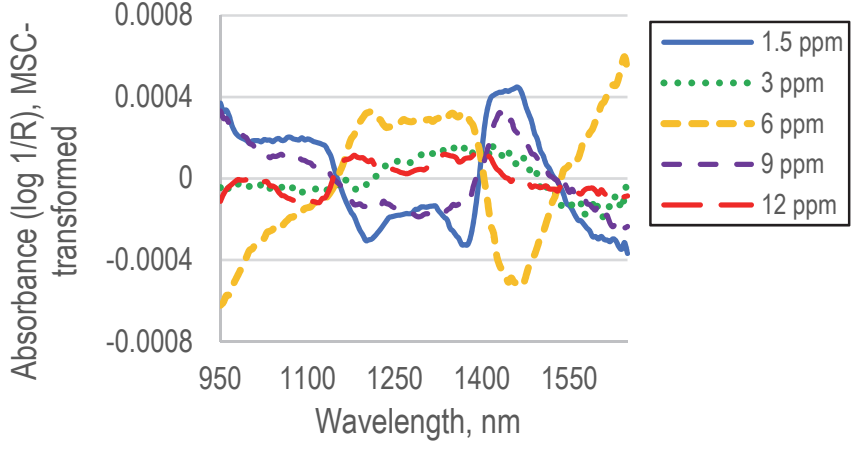

(a2) Spectral difference to control for MSC-transformed spectra of rough rice

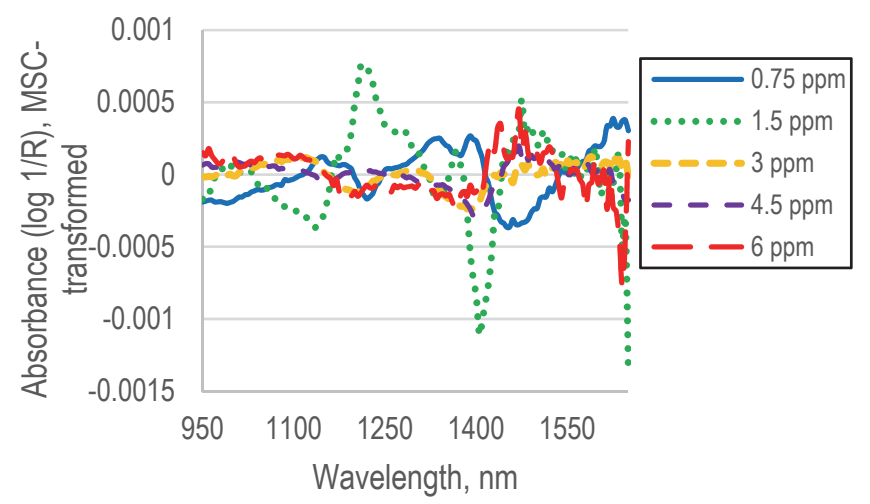

(b2) Spectral difference to control for MSC-transformed spectra of brown rice

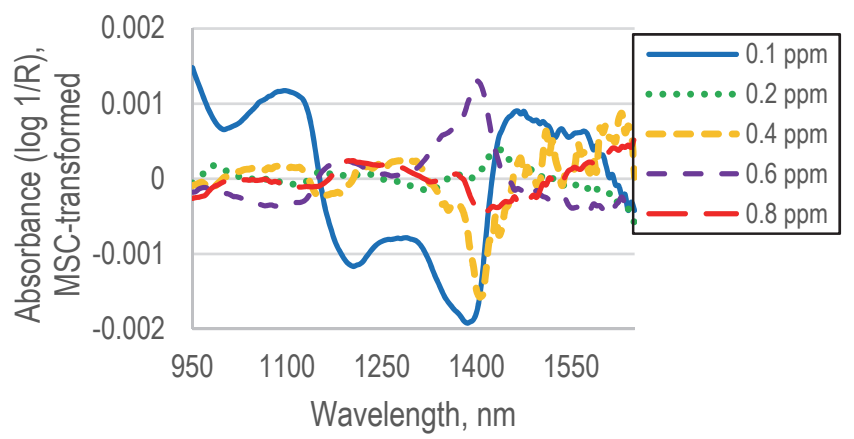

(c2) Spectral difference to control for MSC-transformed spectra of brown rice

Figure 3. MSC-transformed NIR spectra of (a1) rough rice, (b1) brown rice, and (c1) milled rice with varying pesticide residues and the corresponding spectral subtraction of control (no pesticide) to varying pesticide residue levels for (a2) rough, (b2) brown, and (c2) milled rice.

contains fat, fiber, ash, and protein and milled rice, which does not have the hull and bran will have the more exposed starchy endosperm and protein components. These compositional differences may affect the ability of chlorpyrifosmethyl to react and be absorbed by the different rice types, which in turn affects absorbed NIR light.

It is recognized that chlorpyrifos-methyl may not be uniformly distributed in the rice grain yet and may be more concentrated in the external surface of the grain within the $\sim 24 \mathrm{~h}$ of equilibration time prior to spectral data collection. As such, it is probable that prediction accuracies may change with varying equilibration time considering that the penetration depth of NIR light will vary with the type and status of the different rice types. The effects of equilibration time on NIR spectral data and performance for these three rice types were beyond the coverage of this study.

Table 2 summarizes the model prediction statistics developed using all spectra from all five rice varieties, i.e.,
ALLQuanRR, ALLQuanBR, and ALLQuanMR for rough rice, brown rice, and milled rice, respectively, with no independent validation. Also included are the results for the five one-variety-out calibration models, wherein one variety was removed from the calibration model and was used as the independent validation sample, i.e., RR(CL151Val) refers to a rough rice calibration model using all varieties except CL151 which was used for validation.

Considering the low concentrations of chlorpyrifos-methyl applied, especially for milled rice, it would be expected that numerous pre-processing may be needed in order to obtain the NIR signal from chlorpyrifos-methyl. While different pre-processing methods were used in the analysis (MSC, $\mathrm{SNV}$, and mean centering), only the results from the simplest method used, i.e., mean centering, which yielded similar prediction capability as the other pre-processing methods are presented in table 2 . The absorption of chlorpyrifos-methyl into the grain and supposed equilibration within the $24 \mathrm{~h}$ 

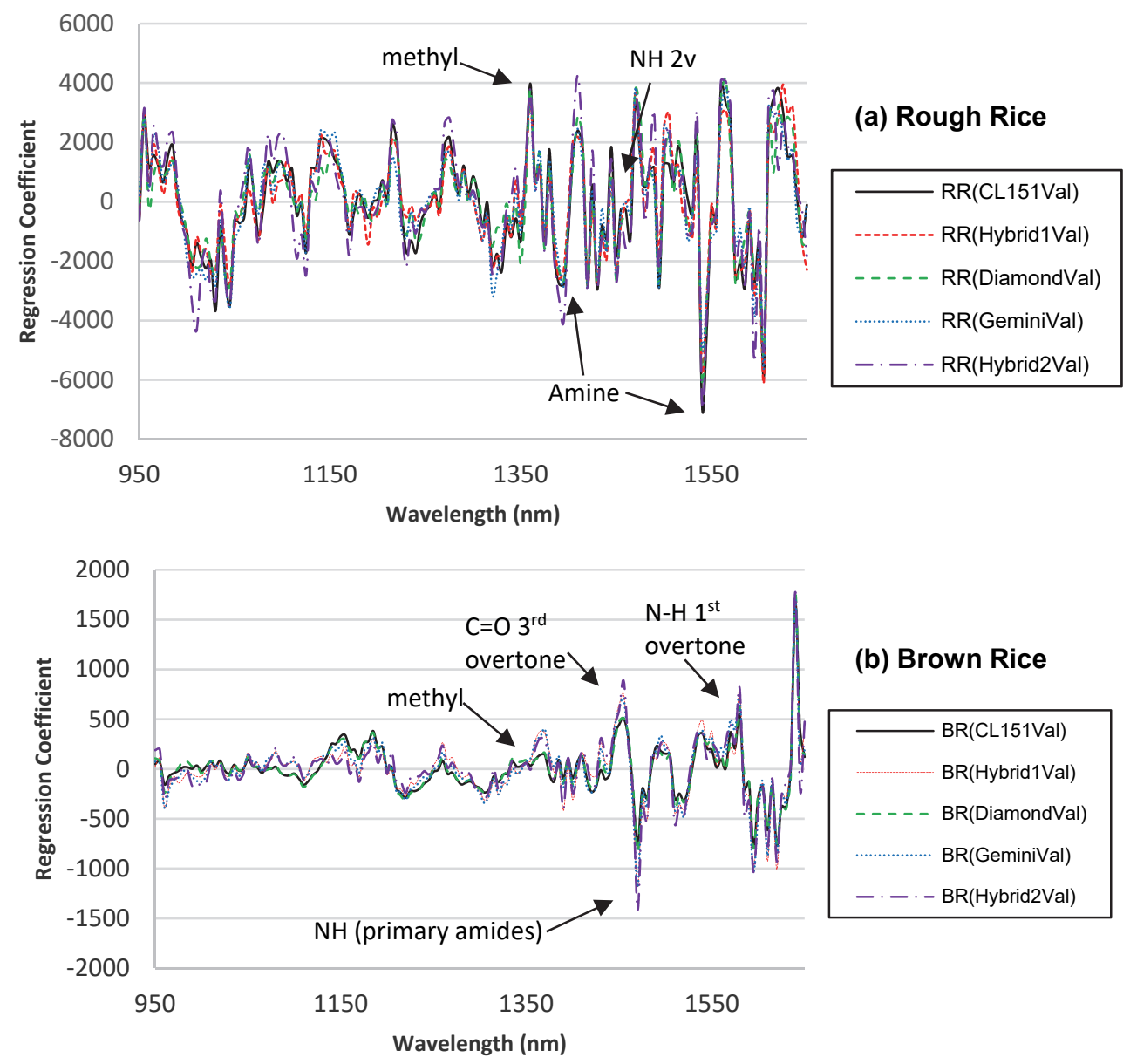

s

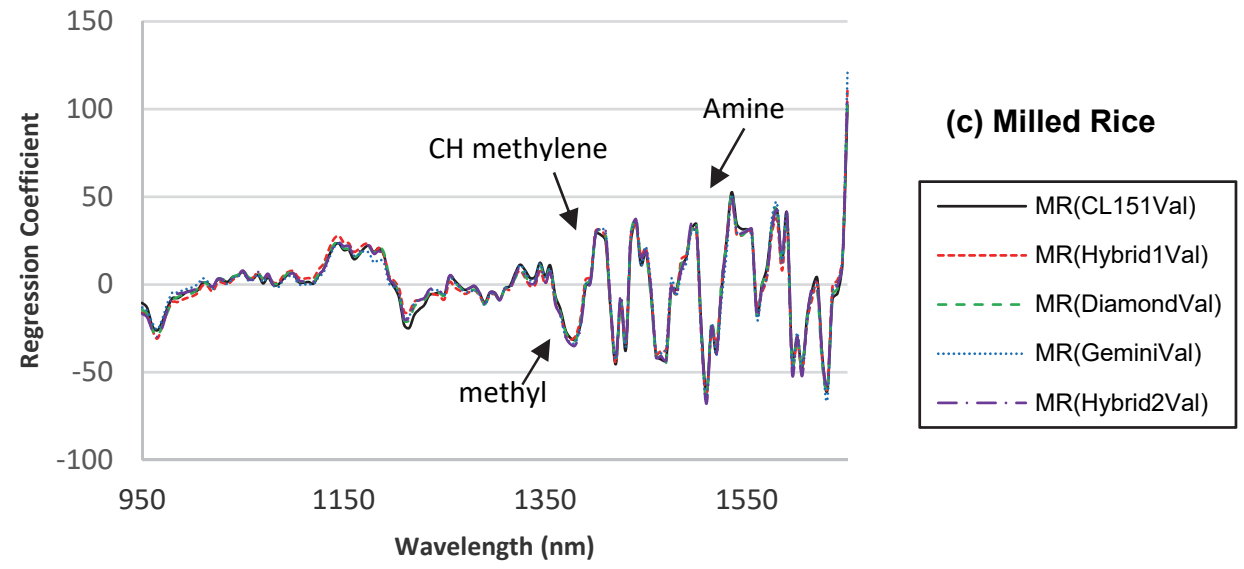

Figure 4. Regression coefficients of calibration models developed for quantitative prediction of concentrations of chlorpyrifos-methyl residues in (a) rough, (b) brown, and (c) milled rice.

equilibration time used may have been incomplete such that chlorpyrifos-methyl residues were concentrated in the grain surface, thus making it possible to be detected by NIR.

The predicted pesticide residue concentrations of independent validation samples against the reference pesticide residue concentration were plotted for each variety; example plots of two randomly-selected varieties, i.e., CL151 and Hybrid 2 varieties for all rice types are shown in figure 5.

\section{Rough Rice}

The wavelengths that contributed to the prediction, as shown in the regression coefficients across the entire wavelength range (fig. 4(a)) were similar across the five one-variety-out calibration models. The ALLQuanRR calibration model for rough rice used spectra from all five rice varieties with 0 to $12 \mathrm{ppm}$ chlorpyrifos-methyl residues. At 10 PLS model factors, the coefficient of multiple determination $\left(\mathrm{R}^{2}\right)$ for the calibration model was 0.78 with root mean square error of calibration (RMSEC) of $1.96, \mathrm{R}^{2}$ for validation of 0.68 and 
Table 2. PLS model prediction statistics for quantitative determination of chlorpyrifos-methyl residues in rough rice, brown rice, and milled rice.

\begin{tabular}{|c|c|c|c|c|c|c|c|c|c|}
\hline \multirow[b]{2}{*}{ Model Description $^{[\mathrm{a}]}$} & \multicolumn{6}{|c|}{ Calibration $^{[\mathrm{b}]}$} & \multicolumn{3}{|c|}{ Independent Validation } \\
\hline & $\mathrm{N}$ & $\mathrm{nF}$ & $\mathrm{R}^{2} \mathrm{Cal}$ & RMSEC & $\mathrm{R}^{2} \mathrm{CV}$ & SECV & $\mathrm{N}$ & $\mathrm{R}^{2}$ & SEP \\
\hline \multicolumn{10}{|l|}{ Rough Rice (0 to $12 \mathrm{ppm})$} \\
\hline ALLQuanRR & 270 & 10 & 0.78 & 1.96 & 0.68 & 2.49 & - & - & - \\
\hline RR(CL151Val) & 216 & 10 & 0.77 & 2.02 & 0.65 & 2.64 & 54 & 0.78 & 2.06 \\
\hline RR(DiamondVal) & 216 & 10 & 0.77 & 2.03 & 0.64 & 2.68 & 54 & 0.71 & 2.31 \\
\hline RR(Hybrid1Val) & 216 & 10 & 0.77 & 2.03 & 0.66 & 2.59 & 54 & 0.84 & 1.76 \\
\hline RR(GeminiVal) & 216 & 10 & 0.78 & 2.00 & 0.66 & 2.62 & 54 & 0.72 & 2.36 \\
\hline RR(Hybrid2Val) & 216 & 10 & 0.82 & 1.81 & 0.72 & 2.36 & 54 & 0.71 & 2.37 \\
\hline \multicolumn{10}{|l|}{ Brown Rice $(0 \text { to } 6 \mathrm{ppm})^{[\mathrm{c}]}$} \\
\hline ALLQuanBR & 269 & 9 & 0.80 & 0.95 & 0.71 & 1.22 & - & - & - \\
\hline BR(CL151Val) & 216 & 8 & 0.78 & 0.99 & 0.70 & 1.24 & 53 & 0.72 & 1.17 \\
\hline BR(DiamondVal) & 215 & 8 & 0.78 & 1.00 & 0.70 & 1.21 & 54 & 0.74 & 1.07 \\
\hline BR(Hybrid1Val) & 215 & 9 & 0.80 & 0.95 & 0.72 & 1.22 & 54 & 0.80 & 0.99 \\
\hline BR(GeminiVal) & 215 & 9 & 0.81 & 0.92 & 0.72 & 1.20 & 54 & 0.73 & 1.12 \\
\hline BR(Hybrid2Val) & 215 & 9 & 0.80 & 0.94 & 0.71 & 1.21 & 54 & 0.80 & 0.95 \\
\hline \multicolumn{10}{|l|}{ Milled Rice (0 to0.8 ppm) } \\
\hline ALLQuanMR & 270 & 7 & 0.76 & 0.14 & 0.69 & 0.17 & - & - & - \\
\hline MR(CL151Val) & 216 & 7 & 0.77 & 0.13 & 0.71 & 0.16 & 54 & 0.69 & 0.16 \\
\hline MR(DiamondVal) & 216 & 7 & 0.76 & 0.14 & 0.68 & 0.17 & 54 & 0.77 & 0.14 \\
\hline MR(Hybrid1Val) & 216 & 7 & 0.77 & 0.14 & 0.70 & 0.16 & 54 & 0.72 & 0.15 \\
\hline MR(GeminiVal) & 216 & 7 & 0.75 & 0.14 & 0.68 & 0.17 & 54 & 0.77 & 0.14 \\
\hline MR(Hybrid2Val) & 216 & 7 & 0.85 & 0.14 & 0.66 & 0.17 & 54 & 0.79 & 0.13 \\
\hline
\end{tabular}

[a] $\mathrm{ALLQuan}=\mathrm{All}$ varieties quantitative; $\mathrm{RR}=$ rough rice, $\mathrm{BR}=$ brown rice; $\mathrm{MR}=$ milled rice.

[b] $\mathrm{N}=$ number of samples for calibration samples; $\mathrm{nF}=$ number of factors; $\mathrm{R}^{2} \mathrm{Cal}=$ coefficient of determination of calibration; $\mathrm{RMSEC}=$ root mean square error of calibration; $\mathrm{R}^{2} \mathrm{CV}=$ coefficient of determination of calibration validation; $n=$ number of samples for validation samples; $\mathrm{R}^{2}=$ coefficient of determination of independent validation; $\mathrm{SEP}=$ standard error of prediction.

[c] One spectral outlier removed from brown rice.

standard error of cross-validation (SECV) of 2.49. The calibration statistics obtained for the five one-variety-out calibration models were similar to those for the ALLQuanRR calibration model. The $\mathrm{R}^{2}$ Cal ranged from 0.77 to 0.82 , RMSEC range of 1.81 to $2.03, \mathrm{R}^{2} \mathrm{CV}$ from 0.64 to 0.72 and SECV of 2.36 to 2.68 . The independent validation results have $\mathrm{R}^{2}$ ranging from 0.70 to 0.84 and standard error of prediction (SEP) of 1.76 to 2.37. The overall calibration performance as shown by the SEP indicates the potential of using NIR spectroscopy for quantifying chlorpyrifos-methyl residues in rough rice; this also provides the user with the information to decide on whether this technique has the sensitivity or is useful for their specific applications. As examples, figures 4(a) and 4(b) provides two independent validation results for prediction of varieties CL151 and Hybrid 2, respectively. The plots show representation of actual versus predicted chlorpyrifos-methyl concentrations in rough rice for CL151 and Hybrid 2, respectively. There are observed differences in the spread in prediction across varieties, which are likewise reflected in the higher $\mathrm{R}^{2}$ for CL151 at 0.78 compared to 0.70 for Hybrid 2.

\section{Brown Rice}

Figure 4(b) shows that the important wavelengths for the detection of chlorpyrifos-methyl in brown rice are similar across the five one-variety-out calibration models. The ALLQuanBR calibration model for brown rice contained spectra from samples with 0 to 6 ppm chlorpyrifos-methyl. At 9 factors, the $\mathrm{R}^{2} \mathrm{Cal}$ was $0.80, \mathrm{RMSEC}=0.95, \mathrm{R}^{2} \mathrm{CV}=$ 0.70 and $\mathrm{SECV}=1.21$. As in the case of rough rice, the calibration statistics obtained for the five one-variety-out calibration models of brown rice were similar to those for the ALLQuanBR calibration model of brown rice. The selected number of factors used in model development varied at $n=$ 8 or 9 . The $\mathrm{R}^{2} \mathrm{Cal}$ for these five models ranged from 0.79 to
0.81 , RMSEC range of 0.92 to $0.996, \mathrm{R}^{2} \mathrm{CV}$ from 0.70 to 0.72 and SECV of 1.20 to 1.24. Results showed good pesticide residue prediction capability among the five varieties of brown rice. For the independent validation, the $\mathrm{R}^{2}$ ranged from 0.72 to 0.80 and SEP ranged from 0.95 to 1.17 indicating the potential of NIR spectroscopy for predicting chlorpyrifos-methyl concentrations in brown rice. Figures 4(c) and 4(d) provides examples of validation results for prediction of pesticide residues for two pre-selected varieties, i.e., CL151 and Hybrid 2, respectively. The difference across varieties are again reflected in the plots; validation for CL151 resulted in lower $\mathrm{R}^{2}$ of 0.72 compared to 0.80 of $\mathrm{Hy}-$ brid 2. This may be due to the $4.5 \mathrm{ppm}$ samples of CL151 being consistently predicted lower ( $\sim 1.5$ to $\sim 4 \mathrm{ppm})$ compared to Hybrid 2 being predicted at $\sim 2$ to $6 \mathrm{ppm}$.

\section{Milled Rice}

As shown in the regression coefficients across the entire wavelength range, the important wavelengths in the prediction of chlorpyrifos-methyl concentrations in milled rice were similar across the five one-variety-out calibration models (fig. 3c). The ALLQuanMR calibration model for milled rice contained spectra from samples with 0 to $0.8 \mathrm{ppm}$ chlorpyrifos-methyl pesticide residues; these are significantly lower than the concentrations present in rough and brown rice. At 7 PLS factors, the $\mathrm{R}^{2} \mathrm{Cal}$ was 0.76 , RMSEC $=0.14, \mathrm{R}^{2} \mathrm{CV}=0.69$, and $\mathrm{SECV}=0.17$. As in the case of rough and brown rice, the calibration statistics obtained for the five one-variety-out calibration models of milled rice were similar to those for the ALLQuanMR calibration model. The selected number of factors used in model development was the same $(n=7)$ across all calibration models. The $\mathrm{R}^{2} \mathrm{Cal}$ for these five models ranged from 0.75 to 0.85 , RMSEC range of 0.13 to $0.14, \mathrm{R}^{2} \mathrm{CV}$ from 0.66 to 0.71 and SECV of 0.16 to 0.17 . For the independent validation, the $\mathrm{R}^{2}$ 

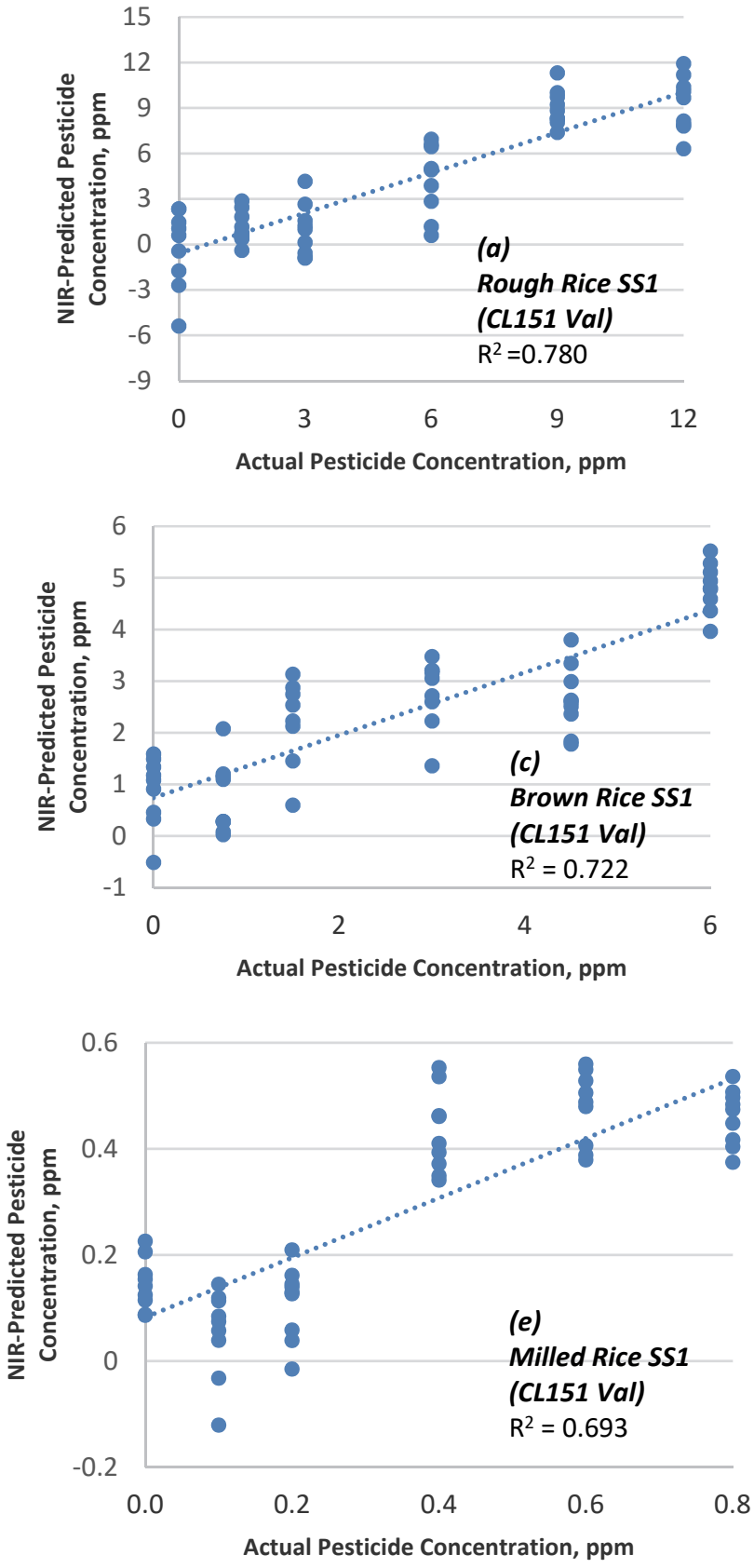
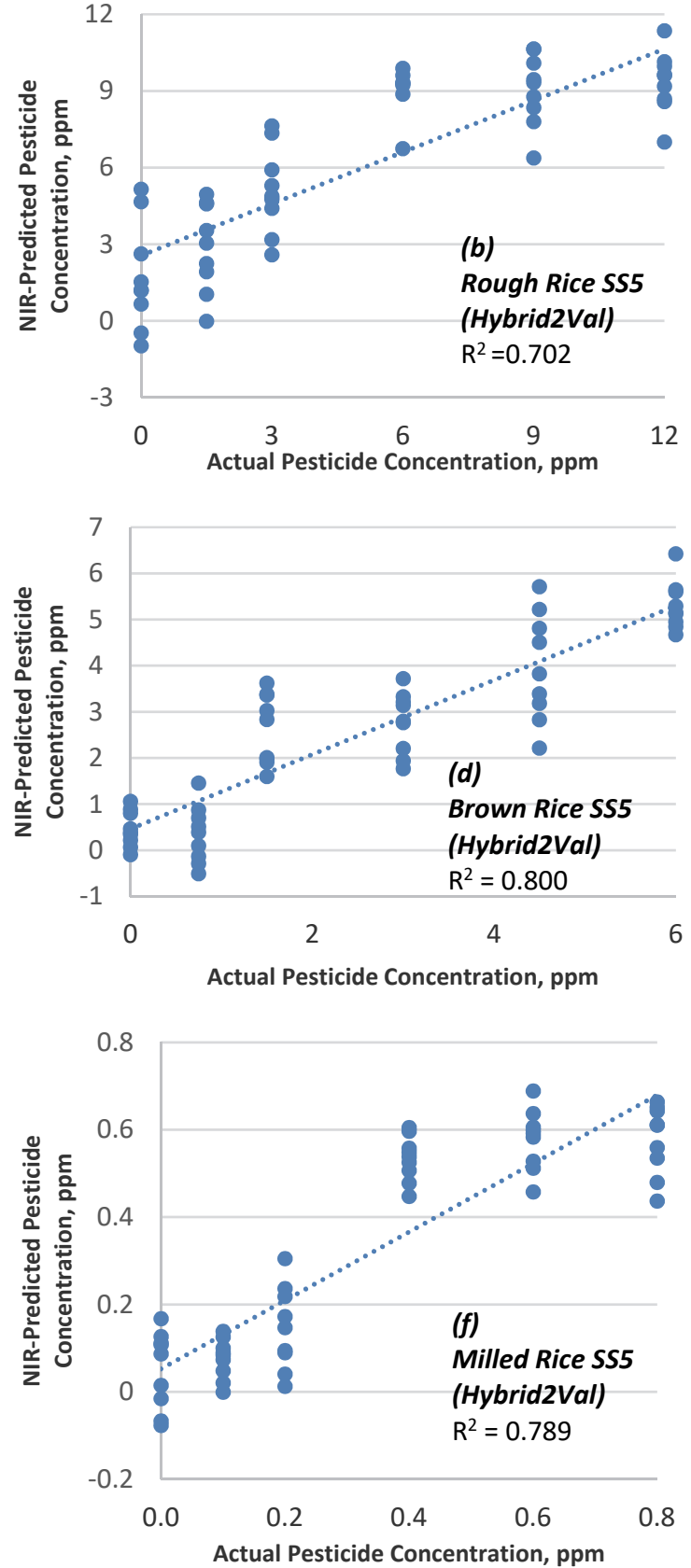

Figure 5. Comparison of actual versus NIR-predicted chlorpyrifos-methyl pesticide concentrations for independent validation for prediction of two randomly selected calibration models of (a and b) rough, (c and d) brown, and (e and f) milled rice.

ranged from 0.69 to 0.79 and SEP ranged from 0.13 to 0.16 . While these statistics indicated that pesticide residues in milled rice may be slightly more difficult to predict compared to rough and brown rice, figures 4(e) and 4(f) which shows examples of validation results for prediction of pesticide residues for two pre-selected varieties still indicated good potential for NIR spectroscopy prediction. The differences in predicted pesticide residues across varieties that were evident in the rough and brown rice were not observed for milled rice. The PLS predictions showed distinct separation in NIR-predicted chlorpyrifos-methyl concentration for the three lower range concentrations ( 0 to $0.2 \mathrm{ppm})$ and higher range ( 0.4 to $0.8 \mathrm{ppm})$.

\section{Qualitative Detection of Pesticide Residues}

For applications that require two-way differentiation between "low" pesticide levels (LPL) in rice samples, which pertains to samples with none or low levels of chlorpyrifosmethyl residues versus "high" pesticide levels (HPL) that pertains to samples with elevated levels of chlorpyrifos-methyl residues, discriminant analysis was used. Table 3 summarizes the prediction statistics for rough, brown, and milled rice. Similar to the sampling used for developing quantitative models, the qualitative calibration models include use of all five rice varieties but without independent validation (ALLQyRR, ALLQyBR, and ALLQyMR models) and the 
Table 3. Discriminant model prediction statistics for qualitative determination of chlorpyrifos-methyl residues in rough rice, brown rice, and milled rice.

\begin{tabular}{|c|c|c|c|c|c|c|}
\hline \multirow[b]{2}{*}{ Description $^{[\mathrm{a}]}$} & \multicolumn{3}{|c|}{ Calibration } & \multicolumn{3}{|c|}{ Independent Validation } \\
\hline & $\begin{array}{c}\text { False } \\
\text { Positive }\end{array}$ & $\begin{array}{c}\text { False } \\
\text { Negative }\end{array}$ & $\begin{array}{l}\text { Overall } \\
\% \mathrm{CC}\end{array}$ & $\begin{array}{c}\text { False } \\
\text { Positive }\end{array}$ & $\begin{array}{c}\text { False } \\
\text { Negative }\end{array}$ & $\begin{array}{l}\text { Overall } \\
\% \mathrm{CC}\end{array}$ \\
\hline \multicolumn{7}{|l|}{$\begin{array}{l}\text { Rough Rice } \\
(\text { Low }=0,1.5, \& 3 \mathrm{ppm} ; \mathrm{High}=6,9, \& 12 \mathrm{ppm})\end{array}$} \\
\hline ALLQualRR & $1 / 135$ & $0 / 135$ & 100 & - & - & - \\
\hline RRQy(CL151Val) & $5 / 108$ & $6 / 108$ & 95 & $6 / 27$ & $6 / 27$ & 77.8 \\
\hline RRQy(DiamondVal) & $0 / 108$ & $0 / 108$ & 100 & $5 / 27$ & $2 / 27$ & 87.0 \\
\hline RRQy(Hybrid1Val) & $3 / 108$ & $6 / 108$ & 96 & $3 / 27$ & $8 / 27$ & 79.6 \\
\hline RRQy(Gemini Val) & $0 / 108$ & $0 / 108$ & 100 & $5 / 27$ & $3 / 27$ & 85.2 \\
\hline RRQy(Hybrid2Val) & $5 / 108$ & $4 / 108$ & 96 & $3 / 27$ & $1 / 27$ & 92.6 \\
\hline \multicolumn{7}{|c|}{$\begin{array}{l}\text { Brown Rice } \\
(\text { Low }=0,0.75, \& 1.5 \mathrm{ppm} ; \mathrm{High}=3,4.5, \& 6 \mathrm{ppm})\end{array}$} \\
\hline ALLQualBR & $0 / 134$ & $0 / 135$ & 100 & - & - & - \\
\hline BRQy(CL151Val) & $11 / 108$ & $5 / 108$ & 93 & $3 / 26$ & $6 / 27$ & 83.3 \\
\hline BRQy(DiamondVal) & $11 / 107$ & $2 / 108$ & 94 & $6 / 27$ & $5 / 27$ & 79.6 \\
\hline BRQy(Hybrid1Val) & $16 / 107$ & $3 / 108$ & 91 & $6 / 27$ & $0 / 27$ & 88.9 \\
\hline BRQy(GeminiVal) & $0 / 107$ & $0 / 108$ & 100 & $4 / 27$ & $6 / 27$ & 81.5 \\
\hline BRQy(Hybrid2Val) & $16 / 107$ & $4 / 108$ & 91 & $4 / 27$ & $2 / 27$ & 88.9 \\
\hline \multicolumn{7}{|c|}{$\begin{array}{l}\text { Milled Rice } \\
(\text { Low }=0,0.1, \& 0.2 \mathrm{ppm} ; \text { High }=0.4,0.6, \& 0.8 \mathrm{ppm})\end{array}$} \\
\hline ALLQualMR & $0 / 135$ & $0 / 135$ & 100 & - & - & - \\
\hline MRQy(CL151Val) & $0 / 108$ & $0 / 108$ & 100 & $0 / 27$ & $10 / 27$ & 95.4 \\
\hline MRQy(DiamondVal) & $0 / 108$ & $0 / 108$ & 100 & $2 / 27$ & $1 / 27$ & 94.4 \\
\hline MRQy(Hybrid1Val) & $0 / 108$ & $0 / 108$ & 100 & $0 / 27$ & $0 / 27$ & 100.0 \\
\hline MRQy(GeminiVal) & $0 / 108$ & $0 / 108$ & 100 & $0 / 27$ & $1 / 27$ & 98.1 \\
\hline MRQy(Hybrid2Val) & $0 / 108$ & $0 / 108$ & 100 & $1 / 27$ & $0 / 27$ & 98.1 \\
\hline
\end{tabular}

[a] $\mathrm{ALLQual}=\mathrm{All}$ varieties qualitative; $\mathrm{Qy}=$ qualitative; $\mathrm{RR}=$ rough rice, $\mathrm{BR}=$ brown rice; $\mathrm{MR}=$ milled rice.

one-variety-out with the variety removed serving as the independent validation sample. With a technique that can discriminate samples with low pesticide residues from those with high levels, it will provide an option, if needed, for analytical tests to be focused on lesser number of samples for further verification. The selected cutoffs of 3, 1.5, and $0.2 \mathrm{ppm}$ for rough, brown, and milled rice, respectively, are stricter than the $10 \mathrm{ppm}$ MRL for rough rice and are equivalent to the MRLs for brown and milled rice.

\section{Rough Rice}

LPL rough rice samples are defined as those that contain $0,1.5$, and $3 \mathrm{ppm}$ chlorpyrifos-methyl residues while HPL rough rice are those that contain 6,9 , and $12 \mathrm{ppm}$. The calibration models showed good potential for the use of NIR spectroscopy for pesticide residue detection as shown by high correct classifications (CC) of $99.6 \%$ for ALLQualRR model and a range of 94.9 to $100 \%$ for the one-variety-out calibration models. The independent validation showed CC range of 77.8 to $92.6 \%$. While these $\% \mathrm{CC}$ may already be considerably high, the wide range may indicate the need to include more representative rice varieties and/or other pesticide residue concentrations to further improve the model.

\section{Brown Rice}

LPL brown rice samples are defined as those that contain $0,0.75$, and $1.5 \mathrm{ppm}$ chlorpyrifos-methyl residues while HPL brown rice are those that contain 3, 4.5, and $6 \mathrm{ppm}$. The calibration model using all varieties (ALLQualBR model), showed $100 \%$ CC. The CC for one-variety-out models were likewise high, i.e., ranging from $90.7 \%$ to $100 \% \mathrm{CC}$. The independent validation showed CC ranging from $79.6 \%$ to $88.9 \%$. As in the case for rough rice, these $\% \mathrm{CC}$ may already be considered high. Likewise, there is an indication that inclusion of more representative samples and/or other pesticide residue concentrations when developing the calibration may help improve the validation results.

\section{Milled Rice}

LPL milled rice samples are defined as those that contain $0,0.1$, and 0.2 ppm chlorpyrifos-methyl residues while HPL milled rice are those that contain $0.4,0.6$, and $0.8 \mathrm{ppm}$. The calibration models that used all varieties (ALLQualMR model) and one-variety-out showed $100 \%$ CC. The independent validation for using the one-variety-out models resulted in $94.4 \%$ to $100 \%$ CC. It may be likely that these high CCs are an indication that with the removal of the hull (present in rough rice) and bran (present in brown rice), the rice matrix becomes less complex and more uniform across varieties, thereby allowing NIR spectroscopy to perform better even though residue levels are quite low.

\section{CONCLUSIONS}

The presence of chlorpyrifos-methyl in all rice types (rough, brown, and milled rice) remains a problem that requires intervention in order to ensure the safety of consumers. The development of instrumentations and techniques that can quickly detect the presence of pesticide residues (both quantitatively and qualitatively) can assist the rice industry in their efforts to monitor pesticide residues for numerous commodities, including rice. This study showed that NIR spectroscopy has the potential to be used for detection of pesticide residues in bulk rice, specifically chlorpyrifosmethyl residues. For quantitative detection, the independent one-variety-out validation based on calibrations developed using PLS analysis showed $\mathrm{R}^{2}$ ranging from 0.702 to 0.839 and SEP of 1.763 to 2.374 for rough rice, $\mathrm{R}^{2}$ ranging from 0.722 to 0.800 and SEP of 0.953 to 1.168 for brown rice, and 
$\mathrm{R}^{2}$ ranging from 0.693 to 0.789 and SEP of 0.131 to 0.164 for milled rice. For qualitative detection, the independent one-variety-out validation based on calibrations developed using discriminant analysis showed overall correct classifications ranging from $77.8 \%$ to $92.6 \%$ for rough rice, $79.6 \%$ to $88.9 \%$ for brown rice, and $94.4 \%$ to $100 \%$ for milled rice. The instrument used is a commercially available tabletop bulk NIR spectrometer; having shown that NIR spectroscopy is capable of detecting differences in concentrations of chlorpyrifos-methyl in different rice types, it is recommended that other NIR design formats, e.g., handheld devices be evaluated to allow measurements outside the laboratory setting and/or development of low-cost instruments that can be focused on detection of specific contaminants in various commodities using targeted wavelengths for detection.

\section{ACKNOWLEDGEMENTS}

Sincerest appreciation to the Department of Science and Technology-Science Education Institute (DOST-SEI), Engineering Research and Development for Technology (ERDT) and USDA-ARS for funding the research and RiceTec, Inc. for providing the experimental rice grain samples. The mention of a trademark or proprietary product does not constitute a guarantee or warranty of the product by the USDA and does not imply its approval for the exclusion of other products that may also be suitable. USDA is an equal opportunity provider and employer.

\section{REFERENCES}

Attaviroj, N., Kasemsumran, S., \& Noomhorm, A. (2011). Rapid variety identification of pure rough rice by Fourier-transform near-infrared spectroscopy. Cereal Chem., 88(5), 490-496. https://doi.org/10.1094/cchem-03-11-0025

Bayer Crop Science,. (2016). Safety data sheet: StorcideTM II grain, bin and warehouse insecticide. Ver. 4. Bayer.

Chuang, Y.-K., Hu, Y.-P., Yang, I. C., Delwiche, S. R., Lo, Y. M., Tsai, C.-Y., \& Chen, S. (2014). Integration of independent component analysis with near infrared spectroscopy for evaluation of rice freshness. J. Cereal Sci., 60(1), 238-242. https://doi.org/10.1016/j.jcs.2014.03.005

Codex Alimentarius Commission. (2017). Joint FAO/WHO Foods Standard Programme Codex Alimentarius Commission. Report of the 49th Session of the Codex Committee on Pesticide Residues. 24-29. CICG, PRC.

EFSA. (2019). Statement: Updated statement on the available outcomes of the human assessment in the context of the pesticides peer review of the active substance chlorpyrifosmethyl. EFSA J. 17(11):21pp.

https://efsa.onlinelibrary.wiley/doi/pdf/10.2903/j.efsa.2019.5908

FAO-WHO. (2009). Pesticide residues in food - 2009. Joint FAO/WHO meeting on pesticide residues: Toxicological evaluations. 16-25. FAO-WHO.

Font, R., Velez, D., Rio-Celestino, M. D., De Haro-Bailon, A., \& Montoro, R. (2005). Screening inorganic arsenic in rice by visible and near-infrared spectroscopy. Microchim. Acta, 151(3), 231-239. https://doi.org/10.1007/s00604-005-0404-x

Gonzalez-Curbelo, M. A., Herrera-Herrera, A. V., Ravelo-Perez, L. M., \& Hernandez-Borges, J. (2012). Sample-preparation methods for pesticide-residue analysis in cereals and derivatives. TrAC, Trends Anal. Chem., 38, 32-51.

https://doi.org/10.1016/j.trac.2012.04.010
Kim, B.-M., Abd El-Aty, A. M., Hwang, T.-E., Jin, L.-T., Kim, Y.S., \& Shim, J.-H. (2007). Development of an

acetylcholinesterase-based detection kit for the determination of organophosphorus and carbamate pesticide residues in agricultural samples. Bull. Korean Chem. Soc., 28(6), 929-935. https://doi.org/10.5012/BKCS.2007.28.6.929

Kolberg, D. I., Prestes, O. D., Adaime, M. B., \& Zanella, R. (2011). Development of a fast multiresidue method for the determination of pesticides in dry samples (wheat grains, flour and bran) using QuEChERS based method and GC-MS. Food Chem., 125(4), 1436-1442. https://doi.org/10.1016/j.foodchem.2010.10.041

Liu, C.-C., Shaw, J.-T., Poong, K.-Y., Hong, M.-C., \& Shen, M.-L. (2006). Wavelength selection for classifying paddy rice by nearinfrared spectroscopy. Cereal Chem., 83(4), 335-339. https://doi.org/10.1094/cc-83-0335

Liu, K., Li, Y., Chen, F., \& Yong, F. (2016). Lipid oxidation of brown rice stored at different temperatures. Int. J. Food Sci. Technol., 52(1), 188-195. https://doi.org/10.1111/ijfs.13265

Mei, A., Rudén, \& Grandjean, P. (2018). Safety of safety evaluation of pesticides: developmental neurotoxicity of chlorpyrifos and chlorpyrifos-methyl. Env. Health, 17(1), 77: 5pp. https://doi.org/10.1186/s12940-018-0421-y

Osborne, B. G., Mertens, B., Thompson, M., \& Fearn, T. (1993). The authentication of basmati rice using near infrared spectroscopy. J. Near Infrared Spectrosc., 1(2), 77-83. https://doi.org/10.1255/jnirs.8

Pareja, L., Fernandez-Alba, A. R., Cesio, V., \& Heinzen, H. (2011). Analytical methods for pesticide residues in rice. $\operatorname{Tr} A C$, Trends Anal. Chem., 30(2), 270-291. https://doi.org/10.1016/j.trac.2010.12.001

PubChem. (no date.). Chemical search: Natl. Center for Biotechnology Information. Natl. Library of Medicine. Retrieved from https://pubchem.ncbi.nlm.nih.gov/

Rungchang, S., Numthuam, S., Charoensook, R., Thongkum, P., \& Junmatong, C. (2018). Method development for pesticide determination in paddy rice using near infrared spectroscopy. Int. J. Agric. Technol., 14(1), 123-129.

Sanyal, D., Rani, A., \& Alam, S. (2009). A multi-residue method for the analysis of organophosphorus residues in cooked and polished rice using accelerated solvent extraction and dispersivesolid phase extraction (D-SPE) technique and uncertainty measurement. J. Environ. Sci. Health, Part B, 44(7), 706-716. https://doi.org/10.1080/03601230903163830

Shenk, J. S., Workman Jr., J. J., \& Westerhaus, M. O. (1992). Application of NIR spectroscopy to agricultural products. In D. A. Burns, \& E. W. Ciurczak (Eds.), Handbook of near-infrared analysis (pp. 383-431). New York, NY: Marcel Dekker.

U.S. EPA. (1984). Health and environmental effects profile for chlorpyrifos and chlorpyrifos-methyl. U.S. Environmental Protection Agency, Washington, D.C., EPA/600/X84/331(NTIS PB88161955).

Workman Jr., J., \& Weyer, L. (2008). Practical guide to interpretive near-infrared spectroscopy. Boca Raton, FL: CRC Press. https://doi.org/10.1201/9781420018318

Xu, W., Liu, X., Xie, L., \& Ying, Y. (2014). Comparison of Fourier transform near-infrared, visible near-infrared, mid-infrared, and Raman spectroscopy as non-invasive tools for transgenic rice discrimination. Trans. ASABE, 57(1), 141-150. https://doi.org/10.13031/trans.57.10363

Zhang, X., Shen, Y., Yu, X.-y., \& Liu, X.-j. (2012). Dissipation of chlorpyrifos and residue analysis in rice, soil and water under paddy field conditions. Ecotoxicol. Environ. Saf., 78, 276-280. https://doi.org/10.1016/j.ecoenv.2011.11.036 